\title{
Disorders of Sex Development: not Always Endocrine Disorders
}

\author{
Amir M. I. Babiker ${ }^{1,2}$ \\ Assistant Professor, Consultant Paediatric Endocrinologist \\ Nasir A.N. Al-Jurayyan ${ }^{1,2}$ \\ Professor, Consultant Paediatric Endocrinologist \\ Hessah, M.N. Al Otaibi ${ }^{1,2}$ \\ Consultant Paediatric Endocrinologist \\ ${ }^{1}$ Division of Paediatric Endocrinology, \\ ${ }^{2}$ Department of Paediatrics, College of Medicine and King Khalid University Hospital, \\ King Saud University, Riyadh, Saudi Arabia \\ Babikeramir@hotmail.com,njurayyan@gmail.com,dralotaibih@yahoo.com
}

\begin{abstract}
Congenital genital abnormalities are of a very complex pathology. In order to clarify their causes, it is important to revert to the genetic conditions and regulation of embryological development. The diagnostic criteria can be complex and costly. We report several patients with various isolated or multiple congenital malformations associated with ambiguous genitalia that can be elucidated by physical examination or condition specific investigations to highlight the importance of considering them in the differential diagnosis of DSD. The data was scrutinized from patients presented to Endocrine and Paediatric clinics at King Khalid University hospital (KKUH), Riyadh, Saudi Arabia, over two decades. Ninety-eight patients aged 1 day to 8 years were evaluated for DSD at KKUH between 1989-2010. Seventy percent ( $n=69$ patients) were genetically females (46XX), while $29.6 \%$ ( $n=29$ patients) had a male genetic sex (46XY). The majority of patients had congenital adrenal hyperplasia. However, 15.2\% ( $n=15$ patients) were diagnosed with isolated or multiple, syndromic or non-syndromic congenital anomalies. We conclude that, especially in a high consanguineous population, DSD can occur due to a wide spectrum of endocrine and non-endocrine causes. There is no substitute to careful history and physical examination in order to help the diagnosis and avoid unnecessary investigations.
\end{abstract}

Keywords: Ambiguous genitalia; Congenital anomalies; DSD; Saudi Arabia; Syndromes.

Abbreviations: $A G$ - Ambiguous genitalia; DSD - Disorders of sex development; KKUH - King Khalid University Hospital

\section{What is known?}

1. Ambiguous genitalia (or as better named disorders of sex development (DSD)) can occur because of endocrine causes (commonest) and non-endocrine causes (such as part of congenital malformations).

2. Clinicians should apply a thorough approach of history taking and physical examination in order to identify, and accordingly investigate, the possible cause of DSD on individual basis.

\section{What is new?}

1. DSD may be frequently associated with localised congenital malformation as reflected in our data over two decades. This higher risk of congenital malformation, we observed in our cohort, could be due to living in high altitudes in some parts of the Middle East, e.g Saudi Arabia, and also because of high incidence of consanguineous marriages.

2. Even rare new entities may be encountered in this part of the world such as: Reminiscent of hydrolethalus and pseudotrisomy 13 syndrome, which was previously reported also from our centre. Clinicians should pay attention to this, to avoid unnecessary long list of investigations of $\mathrm{DSD}$, and to be able to report on new entities.

\section{INTRODUCTION}

Disorders of sex development (DSD) or differences of sex development, also sometimes referred to as disorders of sex differentiation are medical conditions in which the development of reproductive system is affected from even before birth through infancy to young adulthood [8]. More specifically, 
Amir M. I. Babiker et al.

DSD refers to "congenital conditions in which the development of chromosomal, gonadal, anatomical sex is atypical" [18]. There are several types of DSDs with variable effect on the external and internal reproductive organs (Table 1).

Table1. Classifications of disorders of sex development according to karyotype

\begin{tabular}{|c|c|c|}
\hline \multicolumn{3}{|c|}{ 46, XX Karyotype } \\
\hline \multirow[t]{3}{*}{46 XX DSD } & $\begin{array}{l}\text { Congenital Adrenal } \\
\text { Hyperplasia (CAH) }\end{array}$ & $\begin{array}{l}\text { Enzyme Deficiency: } \\
21 \alpha \text {-Hydroxylase } \\
11 \beta \text {-Hydroxylase } \\
3 \beta \text {-Hydroxysteroid dehydrogenase }\end{array}$ \\
\hline & \multicolumn{2}{|c|}{ Ovarian/Adrenal Tumors (mother-child) } \\
\hline & \multicolumn{2}{|c|}{ Exposure to exogenous medication (synthetic progestin preparation) } \\
\hline \multicolumn{3}{|c|}{ Ovotesticular DSD } \\
\hline \multirow[t]{3}{*}{ 46, XY DSD } & $\begin{array}{l}\text { Lack of synthesis of } \\
\text { testosterone }\end{array}$ & 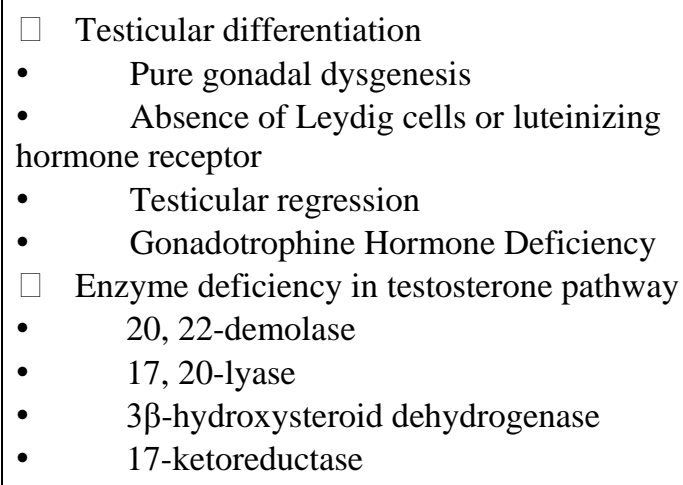 \\
\hline & $\begin{array}{l}\text { Lack of synthesis of } \\
\text { dihydrotestosterone }\end{array}$ & $5 \alpha$-reductase deficiency \\
\hline & $\begin{array}{l}\text { End-organ- } \\
\text { unresponsiveness } \\
\text { (resistance) }\end{array}$ & $\begin{array}{l}\text { - Partial } \\
\text { - Complete }\end{array}$ \\
\hline \multicolumn{3}{|c|}{ Ovotesticular DSD } \\
\hline \multicolumn{3}{|c|}{ Multiple or local congenital anomalies } \\
\hline \multicolumn{3}{|c|}{ Mixed Karyotype } \\
\hline \multicolumn{3}{|c|}{ Ovotesticular DSD 46,XX/46 XY } \\
\hline
\end{tabular}

DSD - Disorders of sex development

Congenital anomaly of the genitalia is a medical term referring to any physical abnormality of the female or male external genitalia present at birth. This is a broad category of conditions. It is a complex medical and social emergency that can create social problems for the child and the family. For this reason, a team of experienced specialists, including neonatologist, geneticist, endocrinologist, paediatric surgeon or urologist, psychologist and social worker should be involved. As a consequence, a life-threatening condition such as adrenal crisis can arise in some conditions, and therefore early recognition is crucial $[1,5,14,24]$.

Since the spectrum of congenital genital anomalies is really broad, a detailed history and physical examination are essential. This would include a family history, e.g. any similar problem or miscarriage, stillbirth or neonatal deaths or infertility. Certain drugs can cross the placenta and interfere with organ development; hence, drug history is also important. Physical examination should concentrate on the description of the genitalia, anorectal structure, any midline defects, hyper pigmentation, and any other congenital anomalies of other parts of the body in a recognisable pattern. Some genital anomalies-like features may simply represent the extremes of prematurity $[4,10,15,16$, and 17]. 
This study aims to highlight and express the importance of including other non-endocrine causes as important differential diagnoses in the management of DSD.

\section{Material AND Methods}

The study group comprised all patients presented for the endocrine and paediatric clinics at King Khalid University hospital (KKUH), Riyadh, Saudi Arabia, over 21 years period (1989-2010) with disorders of sex development. KKUH hospital is one of the main referral hospitals in Riyadh, which receives approximately 5500 deliveries per year on average. Ambiguous genitalia (AG) was considered when there was difficulty in determining the sex on initial examination or when the external genitalia showed significant structure deviation from normal in an apparent male or female patient. The appropriate diagnostic (radiological and serological) tests were done for all patients in our study $[4,5]$.

\section{RESUlTS}

During the period under review, a total of 98 patients were evaluated for $A G$, their age ranged between 1 day and 8 years. Sixty-nine (70.4\%) patients were genetic females (46XX), while twentynine (29.6\%) patients were having a male genetic sex (46XY) (Table 2).

Table2. The genetic sex of the patients with ambiguous genitalia at King Khalid University Hospital, 1989-2010

\begin{tabular}{|l|l|}
\hline Genetic sex & Numbers (Percentage) \\
\hline $46 X X$ & $69(70.4 \%)$ \\
\hline $46 X Y$ & $29(29.6 \%)$ \\
\hline Total & $98(100 \%)$ \\
\hline
\end{tabular}

Table3. Causes of ambiguous genitalia in patients seen at King Khalid University Hospital, 1989-2010

\begin{tabular}{|c|c|c|}
\hline Disorder & No $(\%)$ & No $(\%)$ - Clinical remarks \\
\hline $\mathrm{CAH}$ & $66(67.4 \%)$ & $\begin{array}{l}63(64.2 \%) \text { 46XX DSD - CAH } \\
3(3.2 \%) 46 X Y \text { DSD - } 3 \beta- \\
\text { Hydroxysteroid dehydrogenase } \\
\text { deficiency }\end{array}$ \\
\hline Other DSD & $17(17.4 \%)$ & $\begin{array}{l}7(7.2 \%) \text { - Androgen insensitivity } \\
\text { syndrome } \\
5(5.2 \%) \text { - } 5 \text { alpha reductase } \\
\text { deficiency } \\
1(1 \%) \text { - Persistant Mullarian duct } \\
1(1 \%) \text { - Swyer syndrome } \\
1(1 \%) \text { - Ovotesticular DSD } \\
2(2 \%) \text { - True hermaphrodite }\end{array}$ \\
\hline $\begin{array}{l}\text { AG due to isolated or multiple } \\
\text { congenital Malformation }\end{array}$ & $15(15.2 \%)$ & $\begin{array}{l}4(4.1 \%) \text { - Isolated Cloacal } \\
\text { anomalies } \\
2(2 \%) \text { - Isolated hypospadias } \\
2(2 \%) \text { - Mosaic Turner's } \\
\text { syndrome } \\
2(2 \%) \text { - Multiple congenital } \\
\text { anomalies in reminiscent of } \\
\text { hydrolethalus and pseudotrisomy } \\
13 \text { syndrome } \\
2(2 \%) \text { - isolated clitoral } \\
\text { hypertrophy } \\
1(1 \%) \text { - Prader Willi Syndrome } \\
1(1 \%) \text { - Klinefelter's syndrome } \\
1(1 \%) \text { - Male patient with } \\
\text { extreme prematurity }\end{array}$ \\
\hline Total & $98(100 \%)$ & $98(100 \%)$ \\
\hline
\end{tabular}

AG - Ambiguous genitalia; CAH - Congenital adrenal hyperplasia; DSD - Disorders of sex development

The majority of patients had congenital adrenal hyperplasia (Table 3). Various 15 (15.2\%) patients with congenital anomalies were diagnosed among different series of patients, four with isolated cloacal anomalies, two with isolated hypospadias, one with Prader Willi syndrome, one with Klinefelter's syndrome, two patients were mosaic Turner, two with clitromegally, two patients with 
multiple congenital anomalies observed in reminiscent of hydrolethalus and pseudotrisomy 13 syndrome, and finally one male patient with extreme prematurity (Gestational age- 24 weeks) (Table 3 ). Investigations revealed $46 \mathrm{XY}$ in the latter patient with gonads within the inguinal area and all hormonal investigations were normal. Eventually the gonads descend with phallus enlargement when his prematurity was corrected. Only two patients were evident to have true hermaphroditism by laparoscopic examination and biopsy (Table 3).

\section{Discussion}

Reviewing the wide variety of congenital genital anomalies, it is obvious that the pathology is complex, diagnosis is difficult and in most situations a long treatment is required. The physicians are not always able to establish the diagnosis immediately after birth and a time and resources consuming investigations are requested. The majority of our cases, either $46 \mathrm{XX}$ or $46 \mathrm{XY}$, were abnormally associated with clear endocrinopathy such as congenital adrenal hyperplasia $(\mathrm{CAH})$ or androgen insensitivity syndrome, however, in others there seemed to be no rule [1,3-5,10,14-17,23,24]. In our study, ambiguous genitalia (AG) were associated with localised congenital malformation of the lower gut and urinary system in four patients. Similar results have been reported before from Saudi Arabia $[2,3]$. This can be due to variable factors including higher risk of congenital malformation due to living in high altitudes in some parts of the country and also because of high incidence of consanguineous marriage $[19,22]$. In a study from a high altitude area in Saudi Arabia, a prevalence of 72 cases per 10,000 deliveries of congenital malformations was reported. About $20 \%$ of the anomalies were urogenital [11]. A high incidence of congenital anomalies has also been reported in Western Saudi Arabia. In 5356 of born babies (2004-2005) in a large university hospital, 174 (27.06/1000) live birth and 13 (2.39/1000) stillbirth had congenital anomalies, and parents were consanguineous in $38.8 \%$ of cases [6]. Among the most common systems involved, in that study, were the external genitalia (2.8/1000) and urinary system (2.6/1000) [6].

In general, urogenital sinus and cloacal anomalies are rare. During development in utero, the genitourinary and intestinal tracts initially form together. As development progresses, the genito-urinary bladder, vagina and genitalia are separated from the bowel and intestinal tract by formation of the urorectal septum. In females, the bladder and urethra separate from the vagina $[12,13]$. Multiple congenital anomalies following the pattern of certain genitalia syndromes has been observed as in reminiscent of hydrolethalus and pseudotrisomy 13 syndrome [9]. Pavone et al reported on unbalanced translocation of 46XYt $(7 ; 16)$ [20]. As well, different series of ambiguous genitalia were reported in Klinefelter, Turner and Prader Willi syndromes [7]. Congenital genital malformations with Smith-Lemli Opitz syndrome may include severe underdevelopment of genitalia and/or female appearing external genitalia [21].

There are several literature reports of mosaic Turner patients associated with ambiguous genitalia secondary to the presence of SRY gene. Al Mulhim et al reported in his series two cases of mosaic Turner genotype, one of them had the SRY gene [2].

One of our patients was extremely premature. With the recent and rapid advancement of technology, neonatal services improved a great deal and therefore we will see more premature babies, possibly with incomplete development of genitalia.

\section{Conclusion}

A wide spectrum of causes of DSD was noted at our University Centre in the Middle East, with congenital adrenal hyperplasia being the commonest endocrine disorder among others. However isolated anorectal anomalies with other multiple congenital anomalies that fit into some syndromes such as Smith-Lemli Opitz, Turner and Klinefelter's syndromes were not rare encounters. A detailed history and proper physical examination can aid the diagnosis and help avoiding unnecessary investigations.

\section{ACKNOWLEDGEMENT}

The authors would like to thank and extend their appreciation to the College of Medicine Research Center, Deanship of Scientific Research, King Saud University, Saudi Arabia, for funding this work. 


\section{REFERENCES}

[1] Abdullah, M. A., Saeed, U., Abass, A., Lubna, K., Weam, A., Ali, A. S. (2012). Disorders of sex development among Sudanese children: 5-year experience of a pediatric endocrinology clinic. Journal of Pediatric Endocrinology and Metabolism, 25(11-12), 1065-72.

[2] Al-Mulhin, A., \& Kamal, H. (2010). Ambiguous genitalia in neonates, a 4 years prospective study in localised area. EMHJ, 116(2), 214-217.

[3] Al-Mutair, A., Iqbal. Sakatti, N., \& Ashwal, A. (2004). Cytogenetics and Etiology of Ambiguous Genitalia in 120 Pediatric Patients. Ann. Saudi Med., 24, 368-72.

[4] Al-Jurayyan, N. (2011). Disorders of sex Development: Diagnostic approaches and Management Options: An Islamic Perspective. Malaysian J Med Sci, 18, 4-12.

[5] Al-Jurayyan, N. (2011). Ambiguous Genitalia: Two decades of Experience. Ann. Saudi Med., 31, 284-88.

[6] Alsulaimani, A. A., \& Alzahrani, A. K. (2011). Prevalence of congenital anomalies at high altitude area in Saudi Arabia. Journal of medical research and science, 1(3), 44-52.

[7] Diamond, A., \& Yu, R. (2011). Sexual differentiation: Normal and abnormal. In Wein AJ (Ed.) Campbell-Walsh Urology. 10th ed. Philadelphia: Pa: Saunders Elsevier.

[8] Diamond, M., \& Beh, H. G. (2008). Changes in the management of children with intersex conditions. Nature Clinical Practice Endocrinology \& Metabolism, 4(1), 4-5.

[9] Dinesoy, M., Salih, M., Al-Jurayyan, N., Al-Saadi, M., \& Patel, P. (1955). Multiple congenital malformations in two sibs reminiscent of hydrolethalus and pseudotrisomy 13 syndromes. New syndrome. American journal Med Gent, 56, 317-321.

[10] Endocrinology, S. O., \& Urology, S. O. (2000). Evaluation of the Newborn With Developmental Anomalies of the External Genitalia. Pediatrics, 106(1), 138-142.

[11] Fida, N., Al-Aama, J., Nichols, W., \& Alqahtani, M. (2007). A prospective study of congenital malformations among live born neonates at a University Hospital in Western Saudi Arabia. Saudi Med J., 28(9), 1367-73.

[12] Heller, D. S. (2005). Lower Genital Tract Disease in Children and Adolescents - A review. Journal of Pediatric and Adolescent Gynecology, 18(2), 75-83.

[13] Hendersen, W. (1992). Cloacal malformation: Experienced with 105 cases. J Paediatr Surg, 27 (7), 890-901.

[14] Houk, C. P., \& Lee, P. A. (2012). Update on disorders of sex development. Current Opinion in Endocrinology \& Diabetes and Obesity, 19(1), 28-32.

[15] Hughes, I., Houk, C., Ahmed, S., \& Lee, P. (2006). Consensus Statement on Management of Intersex Disorders. Journal of pediatric urology, 2(3), 148-162.

[16] Hughes, I. A., Nihoul-Fékété, C., Thomas, B., \& Cohen-Kettenis, P. (2007). Consequences of the ESPE/LWPES guidelines for diagnosis and treatment of disorders of sex development. Best Practice \& Research Clinical Endocrinology \& Metabolism, 21(3), 351-365.

[17] Lambert, S. M., Vilain, E. J., \& Kolon, T. F. (2010). A Practical Approach to Ambiguous Genitalia in the Newborn Period. Urologic Clinics of North America, 37(2), 195-205.

[18] Lee, P. A., Houk, C., Ahmed, S., \& Hughes, I. (2006). Consensus Statement on Management Of Intersex Disorders. Pediatrics, 118(2), e488-e500.

[19] Mouzan, M. E., Salloum, A. A., Herbish, A. A., Qurachi, M., \& Omar, A. A. (2008). Consanguinity and major genetic disorders in Saudi children: A community-based crosssectional study. Annals of Saudi Medicine, 28(3), 169.

[20] Pavone, L., Pira, A. L., Caruso, M., Pavone, P., Palumbo, O., Carella, M., et al. (2010). A new cause of ambiguous genitalia: Multiple malformation syndrome related to unbalanced translocation 46XYt $(7 ; 16)$. The internat Journal of Pediarics and Neonatology, 12(2). Retrieved May 8, 2014, from http://ispub.com/IJPN/12/2/6193

[21] Richard, I. K., \& Raoul, C. M. (2000). The Smith-Lemli-Opitz syndrome. J Med Genet, 37, 321335.

[22] Saedi-Wong, S., Al-Frayh, R., \& Wong, N. (1989). Socio-economic epidemiology of consanguineous mating in the Saudi Arabian population. J Asian Afr Studies, 24, 247-51.

[23] Saenger, P. (2001). Physiology of sexual determination and differentiation. In Brook CGD, Hindmarsh PC (Eds.). Clinical Pediatric Endocrinology (pp. 60-76). Oxford (GB): Blackwell Scientific.

[24] Sax, L. (2002). How common is Intersex? A response to Anna Fausto-Sterling. J Sex Res., 39, 174-78. 